disease. J Crohns Colitis, 2013. 7(12): p. 982-1018.

7. Gajendran, M., et al., $A$ comprehensive review and update on Crohn's disease. Dis Mon, 2018. 64(2): p. 20-57.

8. Gajendran, M., et al., A comprehensive review and update on ulcerative colitis(). Dis Mon, 2019. 65(12): p. 100851.
9. Feakins, R.M. and G. British Society of Inflammatory bowel disease biopsies: updated British Society of Gastroenterology reporting guidelines. J Clin Pathol, 2013. 66(12): p. 1005-26.

10. M'Koma, A.E., Inflammatory bowel disease: an expanding global health problem. Clin Med Insights Gastroenterol, 2013. 6: p. 33-47.

\title{
SO SÁNH MộT Số TÁC DUUNG KHÔNG MONG MUỐN CỦA PHƯƠNG PHÁP GÂY TÊ TỦY SỐNG - NGOÀI MÀNG CỨNG PHỐI HỢP VỚI GÂY TÊ TỦY SỐNG ĐƠ'N THUẦN ĐỂ MỔ LẤY THAI TRÊN SẢN PHỤ CÓ NGUY CƠ CAO TỤT HUYẾT ÁP
}

\section{TÓM TẮT}

Mục tiêu: So sánh một số tác dung không mong muốn của phương pháp gẩy tê tủy sổng - ngoài màng cứng phối hợp với gây tê tủy sống đơn thuần để vô cảm cho mố lấy thai ở sản phụ có nguy cơ cao tụt huyết áp. Đối tượng, phương pháp nghiên cứu: Nghiên cứu tiến hành trên 60 sản phụ có chỉ định mổ lấy thai chủ động, có một trong các yếu tố nguy cơ cao tụt huyết áp sau gây tê tuỷ sông: đa thai, đa ối, thai to, được chia ngẫu nhiên thành hai nhóm để thực hiên 2 kỹ thuật vô cảm khác nhau: nhóm I gây tê tuỷ sống với liều bupivacaine theo chiều cao của bệnh nhân(cao <150cm: 7mg, từ 150 - 160cm: $8 \mathrm{mg}$, $>160 \mathrm{~cm}$ : $8,5 \mathrm{mg}$ ) và nhóm II gây tê tuỷ sống liều $5 \mathrm{mg}$ bupivacaine phối hợp với tê ngoài màng cứng $10 \mathrm{ml}$ Lidocaine $1 \%$ with adrenaline 1: 200000 , cả hai nhóm đều đước tiêm dưới nhên $30 \mathrm{mcg}$ fentanyl. Các thuốc co mạch sẽ được dùng điều chỉnh theo mạch, huyết áp của sản phụ. Các tác dung không mong muốn trên me và con được theo dõi liên tục trong 48 giờ sau mổ. Kết quả: Phương pháp gây tể tuỷ sống ngoài màng cứng phối hợp có tỷ lệ nôn, buồn nôn là $6,67 \%$ so với $23,3 \%$ ở nhóm gây tê tủy sống đơn thuân $(p<0,05)$. Tỷ lệ ngứa, rét run ở nhóm gây tê tuỷ sống - ngoài màng cứng phối hợp là $23,3 \%$ và $13,3 \%$ so với $26,6 \%$ và $26,6 \%$ ở nhóm gây tê tủy sống đơn thuần; không găp bênh nhân nào bi suy hô hấp, an thần sâu, đau đầu, bí tiểu ở cả hai nhóm. Điểm Apgar phút thứ nhất và phút thứ 5 của trẻ sơ sinh ở hai nhóm đều $>8$, không có sự khác biệt). Không gặp các biến chứng nguy hiểm trên mẹ và con. Kết luận: Phương pháp gây tê tuỷ sống - ngoài màng cứng phối hợp ít găp nôn, buồn nôn hơn so với phương pháp gây tể tủy sống đơn thuần. Các tác dụng không mong muốn khác trên mẹ và con không

\section{*Trường ĐHY Hà Nội}

**Bệnh viện Đa khoa Hồng Ngọc

Chịu trách nhiệm chính: Nguyên Đức Lam

Email: lamgmhs75@gmail.com

Ngày nhận bài: 14.12 .2020

Ngày phản biên khoa hoc: 25.01.2021

Ngày duyệt bài: 11.2.2021

\section{Nguyễn Đức Lam*, Nguyễn Thị Thu Ba**}

có sự khác biệt giữa hai nhóm. Không gặp các biến chứng nguy hiểm trên mẹ và con.

Tư khóa: Mổ lây thai, gây tê tuỷ sống, gây tê tuỷ sống - ngoài màng cứng phối hợp, tác dụng không mong muốn.

\section{SUMMARY \\ THE COMPARISON OF THE SIDE EFFECTS OF COMBINED SPINAL EPIDURAL ANESTHESIA VERSUS SPINAL ANESTHESIA FOR CESAREAN SECTION IN PREGNANT WOMEN WITH HIGH RISK OF HYPOTENSION}

Objective: To compare the side effects of combined spinal epidural anesthesia versus spinal anesthesia for cesarean section in pregnant women with high risk of hypotension. Methods: 60 pregnant women with high risk of hypotension (polyhydramnios, macrosomia or twins) underwent elective cesarean delivery were enrolled into this prospective, randomized, double-blind study. Patients were randomly divided into spinal anesthesia group (Group I) or combined spinal - epidural anaesthesia - CSE group (Group II). Group I received bupivacaine either $7 \mathrm{mg}, 8 \mathrm{mg}$ or $8,5 \mathrm{mg}$ bupivacaine depending on the heigh of patients $(<150 \mathrm{~cm}, 150-160 \mathrm{~cm},>160 \mathrm{~cm})$ with fentanyl 30mcg ; Group II received bupivacaine 5 $\mathrm{mg}$ with fentanyl $30 \mathrm{mcg}$ followed by epidural $1 \%$ lidocaine $10 \mathrm{~mL}$ with adrenaline 1:200 000 . The side effects were recorded during the surgery and 48 hours after surgery. Results: The rate of vomiting and nausea was $6.67 \%$ in CSE group and was $23.3 \%$ in the spinal anesthesia group ( $p<0.05)$. The rates of pruritus and chills in the group of combined spinalepidural anesthesia group were $23.3 \%$ and $13.3 \%$ compared with $26.6 \%$ and $26.6 \%$ in spinal anesthesia group. No patient suffered from respiratory distress, deep sedation, headache, and urinary retention in both groups. The infants' 1 st and 5th minute Apgar scores in both groups were $>8$, no significant difference). No dangerous complication of mothers and newborns was recognized. Conclusions: The rate of vomiting and nausea in CSE group was lower than in spinal anesthesia group, $p<0.05$. Other side 
effects on mothers and newborns did not differ between the two groups. No dangerous complication on mothers and newborns was recognized.

Keywords: Cesarean section, spinal anaesthesia, combined spinal epidural anesthesia, side effects.

\section{I. ĐĂT VẤN ĐỀ}

Tụt huyết áp sau gây tê tủy sống để mổ lấy thai là tác dụng không mong muốn khá thường gặp trong gây tê tủy sống sản khoa, tỷ lệ này có thể lên tới $80 \%$, tụt huyết áp nặng có thể gây trụy mạch, ngừng tuần hoàn, mất ý thức, viêm phổi hít ở người mẹ và có thể gây thiếu oxy, toan hoá, tổn thương thần kinh ở thai nhi[1]. Một trong các cơ chế gây tụt huyết áp nặng ở sản phụ sau gây tê tủy sống là do "Hội chứng chèn ép chủ". Theo Corke $\mathrm{BC}$, các sản phụ có nguy cơ cao tụt huyết áp sau gây tê tủy sống để mổ lấy thai là: các sản phụ đa thai, đa ối, thai to... do tình trạng chèn ép tĩnh mạch chủ nặng nề hơn [2]. Vì vậy, các phương pháp nhằm hạn chế tụt huyết áp ở các đối tượng sản phụ này là đặc biệt cần thiết để đảm bảo an toàn cho cả me và con. Tê tuỷ sống với liều thấp thuốc tê là một phương pháp hiệu quả để giảm những biến động huyết động do tê tuỷ sống gây ra cho mổ lấy thai [3. Để đạt được độ tê mong muốn tê tủy sống liều thấp cần phối hợp với tê ngoài màng cứng phối hợp bởi có thể tiêm thêm thuốc tê qua ngoài màng cứng khi mức tê chưa đủ mà không làm tăng tác dụng phụ của hai phương pháp này [4]. Đã có nhiều nghiên cứu về gây tê tủy sống và ngoài màng cứng phối hợp để giảm liêu thuốc tê khi gây tê tủy sống nhưng chưa có nghiên cứu đánh giá các tác dụng không mong muốn của phương pháp này trên các sản phụ có nguy cơ cao tụt huyết áp khi gây tê tủy sống. Vì vậy, chúng tôi tiến hành nghiên cứu này nhằm mục tiêu: So sánh một số tác dụng không mong muốn của phương pháp gây tê tưy sống -ngoài màng cứng phối hợp với gây tê tưy sống đơn thuần để vô cảm cho mổ lây thai ở sản phu có nguy cơ cao tụt huyêt áp.

\section{II. ĐốI TƯợNG VÀ PHƯƠNG PHÁP NGHIÊN CỨU}

1. Đối tượng nghiên cứu. Nghiên cứu được tiến hành trên 60 sản phụ có chỉ định mổ lấy thai chủ động tại Khoa Gây mê hồi sức, Bệnh viện Phụ sản Hà Nội từ tháng 1/2020 đến tháng $8 / 2020$.

- Tiêu chuẩn lựa chọn: Các sản phụ có nguy cơ cao bị tụt huyết áp khi gây tê tủy sống: đa thai (từ hai thai trở lên), đa ối (chỉ số ối AFI trên $250 \mathrm{~mm}$ ) không có dị tật thai nhi đã được chẩn đoán, thai to (ước tính cân nặng con >3,5 $\mathrm{kg})$; ASA I,II.

- Tiêu chuẩn loại trừ: Các sản phụ có bệnh lý như: tiền sản giật nặng, suy tim, bệnh lý tim có tăng áp động mach phổi, viêm gan, suy thận, Basedow tiến triển, sản phụ có chống chỉ định của gây tê tủy sống và ngoài màng cứng, có mất máu quá $500 \mathrm{ml}$ trong mổ, sản phụ không đồng ý tham gia nghiên cứu.

*Phương pháp: thử nghiệm lâm sàng, ngẫu nhiên, có so sánh.

*Cách thức tiến hành: Bênh nhân được lựa chọn vào nghiên cứu và đồng ý tham gia nghiên cứu sẽ được bốc thăm ngẫu nhiên để chia thành hai nhóm bằng nhau. Cả hai nhóm đều được chuẩn bị khám, kiểm tra xét nghiệm, giải thích phương pháp gây tê, đặt đường truyền tĩnh mạch kim G18, truyền dịch Ringerlactac $10 \mathrm{ml} / \mathrm{kg}$, theo dõi $\mathrm{SpO} 2$, huyết áp, điện tim, gây tê bệnh nhân ở tư thế nằm nghiêng trái cong lưng tôm hoặc tư thế ngồi đầu cúi.

- Nhóm I (Nhóm gây tê tủy sông đơn thuần): Tiến hành gây tê tủy sống ở L2-L3. Liều Bupivacaine tính theo chiều cao (Bệnh nhân cao < 150cm: $7 \mathrm{mg}$, từ $150-160 \mathrm{~cm}: 8 \mathrm{mg}$, cao > $160 \mathrm{~cm}: 8,5 \mathrm{mg}$ ) phối hợp với 0,03mg Fentanyl.

- Nhóm II (Nhóm gây tê tủy sống - ngoài màng cứng phối hợp): gây tê ngoài màng cứng ở L2-3, xác định khoang ngoài màng cứng bằng kỹ thuật mất sức cản với bơm tiêm chứa dịch $\mathrm{NaCl} 0,9 \%$. Luồn catheter lên phía đầu sản phụ và để sâu $3-5 \mathrm{~cm}$ trong khoang ngoài màng cứng, dùng liêu test là $60 \mathrm{mg}$ Lidocain $2 \%$, gây tê tủy sống ở L3-4 với $5 \mathrm{mg}$ Bupivacaine và 0,03mg fentanyl, sau đó tiêm thêm $100 \mathrm{mg}$ lidocaine $2 \%$ qua catheter ngoài màng cứng và đánh giá mức độ ức chế cảm giác 2 phút/lần. Bổ sung các liều thuốc tê Lidocain $2 \%$ mỗi lần 40 $\mathrm{mg} /$ cách 2-4 phút cho đến khi ức chế cảm giác đau đến T6.

Tất cả các bênh nhân đều được theo dõi mạch, huyết áp, nhịp tim 2 phút 1 lần trong 10 phút đâu tiên, 5 phút 1 lần cho tới kết thúc phẫu thuật, mức ức chế cảm giác, vận động và các tác dụng không mong muốn tại các thời điểm của phẫu thuật và 24 giờ đầu sau mổ. Sử dụng các thuốc vận mạch để duy trì huyết áp tâm thu trên $10 \%$ huyết áp nền của bệnh nhân bằng ephedrin hoặc phenylephrin. 


\section{KẾT QUẢ NGHIÊN CứU}

1. Đặc điểm của đối tượng nghiên cứu

Bảng 1. Đăc điểm của đối tướng nghiên cứu

\begin{tabular}{|c|c|c|c|}
\hline Thông số NC & Nhóm GTTS (n = 30) & Nhóm GTTS+NMC (n = 30) & p \\
\hline BMI & $21,35 \pm 1,40$ & $21,15 \pm 1,23$ & $>0,05$ \\
\hline Chiêuu cao (m) & $1,59 \pm 0,49$ & $1,57 \pm 0,06$ & $>0,05$ \\
\hline Tuối (năm) & $31,433 \pm 5,56$ & $28,57 \pm 4,26$ & $>0,05$ \\
\hline Tuối thai (tuần) & $38,87 \pm 1,19$ & $38,77 \pm 1,33$ & $>0,05$ \\
\hline Đa thai & $2(6,6 \%)$ & $5(16,6 \%)$ & $>0,05$ \\
\hline Con to $(>3500 \mathrm{~g})$ & $24(80 \%)$ & $23(76,6 \%)$ & $>0,05$ \\
\hline Đa ối & $3(10 \%)$ & $6(20 \%)$ & $>0,05$ \\
\hline
\end{tabular}

Nhận xét: Không có sự khác biệt có ý nghĩa thống kê về các đặc điếm của bệnh nhân ở hai nhóm.

2. Ảnh hưởng trên hô hấp

\section{1. Ảnh hưởng lên tần số thở}

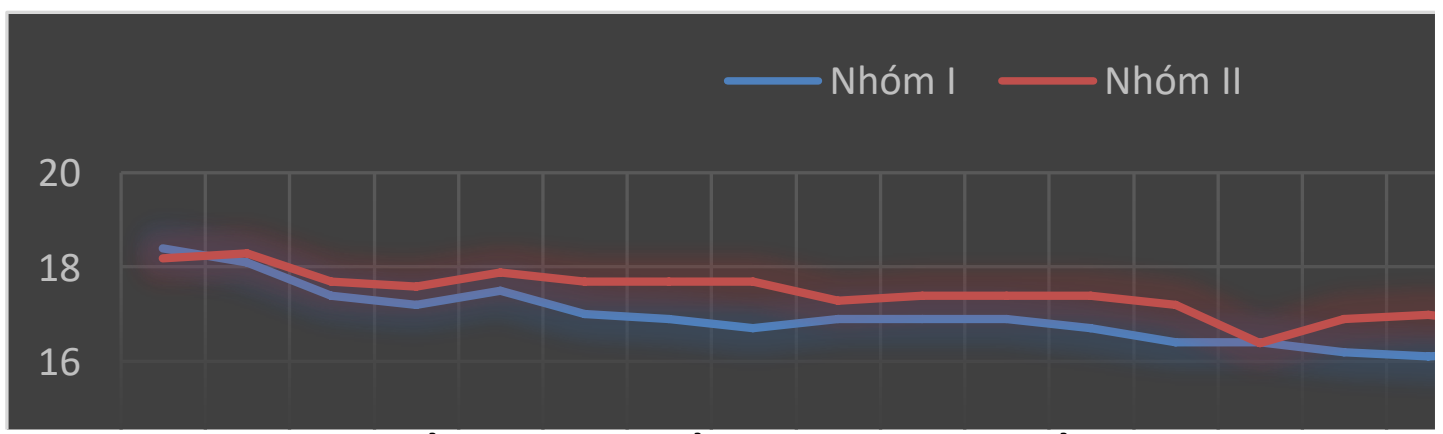

\section{Biểu đồ 1. Thay đổi tân số thở trong mổ}

Nhận xét: Tần số thở của các bệnh nhân ở hai nhóm có xu hướng giảm dần và trở về bình thường. Không có sự khác biệt có ý nghĩa giữa hai nhóm tại tất cả các thời điểm nghiên cứu.

\section{2. Ảnh hưởng lên bão hòa oxy mao mạch}

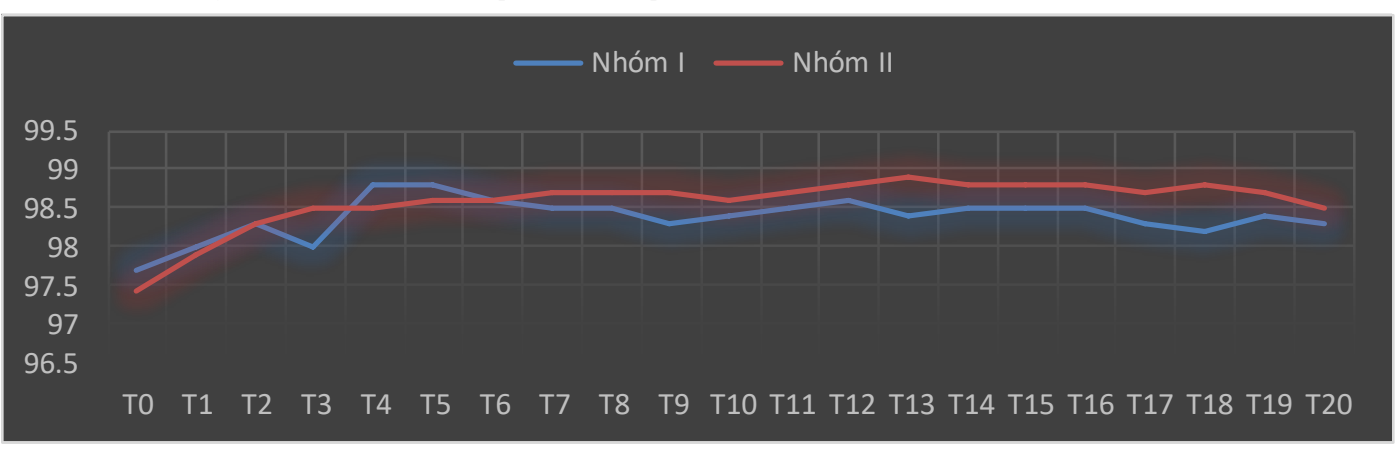

Biểu đồ 2. Thay đổi tần bão hòa oxy trong mổ

Nhận xét: Không có sự khác biệt về bão hòa oxy của các bệnh nhân hai nhóm tại tất cả các thời điểm nghiên cứu.

\section{Các tác dụng không mong muốn khác}

Bảng 3.2. Tác dụng không mong muốn trên me

\begin{tabular}{|c|c|c|c|}
\hline Thông số NC & Nhóm GTTS (n = 30) & Nhóm GTTS+NMC (n = 30) & p \\
\hline An thần sâu & $0(0 \%)$ & $0(0 \%)$ & $>0,05$ \\
\hline Suy hố hấp & $0(0 \%)$ & $0(0 \%)$ & $>0,05$ \\
\hline Ngứa & $8(26,6 \%)$ & $7(23,3 \%)$ & $>0,05$ \\
\hline Rét run & $8(26,6 \%)$ & $4(13,3 \%)$ & $>0,05$ \\
\hline Buồn nôn, nôn & $7(23,3 \%)$ & $2(6,67 \%)$ & $<0,05$ \\
\hline Bí tiểu & $0(0 \%)$ & $0(0 \%)$ & $>0,05$ \\
\hline Dau đâu & $0(0 \%)$ & $0(0 \%)$ & $>0,05$ \\
\hline
\end{tabular}


Nhận xét: Tỷ lệ nôn, buồn nôn của nhóm gây tê tủy sống - ngoài màng cứng phối hợp thấp hơn so với nhóm gây tê tủy sống đơn thuần.

Bảng 3.3. Tinh trang trẻ sơ sinh

\begin{tabular}{|c|c|c|c|}
\hline Thông số NC & $\begin{array}{c}\text { Nhóm GTTS } \\
(\mathbf{n = 3 0 )}\end{array}$ & $\begin{array}{c}\text { Nhóm GTTS+NMC } \\
(\mathbf{n = 3 0 )}\end{array}$ & $\mathbf{p}$ \\
\hline Hồ trợ hô hấp & $0(0 \%)$ & $0(0 \%)$ & $>0,05$ \\
\hline Apgar 1 phút $>8$ & $30(100 \%)$ & $30(100 \%)$ & $>0,05$ \\
\hline Apgar 5 phút >8 & $30(100 \%)$ & $30(100 \%)$ & $>0,05$ \\
\hline Cân nặng trung bình $(\mathrm{kg})-1$ thai & $3,704 \pm 0,325$ & $3,772 \pm 0,244$ & $>0,05$ \\
\hline Cân nặng trung bình con $(\mathrm{kg})-$ đa thai & $2,67 \pm 0,245$ & $2,62 \pm 0,125$ & $>0,05$ \\
\hline
\end{tabular}

Nhân xét: Ở cả 2 nhóm không trẻ nào có điếm Apgar < 8 điếm ở phút thứ 1, không có trẻ nào cần sự hỗ trợ hô hấp. Chỉ số Apgar của trẻ sơ sinh ở 2 nhóm không có sự khác biệt với $p>0.05$

\section{BÀN LUÂN}

Kết quả ở bảng 3.1. cho thấy: Không có sự khác biệt có ý nghĩa thống kê giữa hai nhóm nghiên cứu về các đặc điểm chung như: tuổi mẹ, tuổi thai, chiều cao, cân nặng, BMI... Tỷ lệ bệnh nhân có các yếu tố nguy cơ tụt huyết áp cũ̉ng không có sự khác biệt giữa nhóm I và nhóm II, phần lớn bệnh nhân có thai to $80 \%, 10 \%$ đa thai và $10 \%$ đa ối.

\section{Tác dụng không mong muốn trên người me}

1.1. Ảnh hưởng lên hô hấp. Trong nghiên cứu của chúng tôi, không gặp bệnh nhân nào ở cả hai nhóm có biểu hiện khó thở, suy hô hấp, giảm tần sỗ thở < 10 lần/phút, tụt bão hoà oxy mao mạch (SPO2<90 \%), cũng không gặp bệnh nhân nào phải hỗ trợ hô hấp trong và sau mổ. Nguyên nhân gây suy hô hấp sau gây tê tủy sống, gây tê ngoài màng cứng thường là do: Thuốc tê lan lên cao khi gây tê tủy sống mức cao, liều cao hoă̆c gây tê ngoài màng cứng tiêm nhầm thuốc tê vào khoang dưới nhện (gây tê tuỷ sống toàn bộ) gây ức chế trung tâm hô hấp, ức chế cơ hoành... Trong nghiên cứu của chúng tôi, không có bệnh nhân nào có mức ức chế cảm giác lên trên $D 2$, do đó, không gặp biến chứng suy hô hấp trong mổ. Suy hô hẩp sau mổ lây thai ở bệnh nhân được vô cảm bằng gây tê tủy sống, gây tê ngoài màng cứng cũng có thể do sử dụng morphin liều thấp khi gây tê tủy sống hoặc morphin tiêm ngoài màng cứng vì morphin gẩy ức chế trung tâm hô hấp ở hành não, ở đây chúng tôi không dùng morphin tuỷ sống hoặc morphin ngoài màng cứng nên hạn chế được biến chứng này. Ngoài ra, suy hô hấp cũng còn có thể do phù phổi cấp khi bù dịch tinh thể quá nhanh, chúng tôi có sử dụng dịch truyền nhanh để nâng huyết áp nhưng có kết hợp với thuốc co mạch (ephedrin, phenylephrin), do đó, lượng dịch truyền không quá nhiêu nên không gây biến chứng này. Gây tê tủy sống, ngoài màng cứng phối hợp có tỷ lệ tự huyết áp thấp hơn so với gây tê tủy sống đơn thuân nên nguy cơ quá tải dịch cũng sẽ thấp hơn.

1.2. Tác dụng an thân. Trong nghiên cứu của chúng tôi có sử dụng fentanyl cho cả nhóm gây tê tủy sống đơon thuần và nhóm gây tê tủy sống - ngoài màng cứng phối hợp, đây là thuốc họ morphin nên thuốc cũng có tác dụng ức chế chọn lọc trên hê thần kinh trung ương, tác dụng lên hệ limbic, do đó, có tác dụng an thần. Tuy nhiên, tất cả các bệnh nhân ở hai nhóm của chúng tôi đều tỉnh táo, không gặp trường hợp nào bị an thần sâu (ngủ gà hoặc ngủ khó đánh thức) phải điều trị.

1.3. Nôn, buồn nôn. Nôn là môt trong những tác dụng không mong muốn thường gặp nhất trong gây mê và gây nên khó chịu cho người bệnh chỉ sau đau. Nôn, buồn nôn có thể xảy ra trong mổ hoặc sau mố. Nếu xảy ra trong mổ ngay sau gây tê thường do tụt huyết áp gây thiếu máu não gây kích thích trung tâm nôn ở hành não.Trong nghiên cứu này, tỷ lệ bệnh nhân nôn hoặc buồn nôn ở nhóm 1 là 23,3\%, nhóm 2 là $6,67 \%$. Kết quả này tương đương với Nguyễn Đức Lam là $13,33 \%$ và $6,67 \%[7]$. Trong nghiên cứu của chúng tôi, nhóm gây tê tủy sống - ngoài màng cứng phối hợp có tỷ lệ tụt huyết áp là $10 \%$ thấp hơn nhóm gây tê tủy sống $(66,7 \%)$ nên tác dụng phụ nôn và buồn nôn cũng ít hơn $(6,67 \%$ so với $23,33 \%)$. Đây cũng là một trong những ưu điểm của phương pháp gây tê tủy sống - ngoài màng cứng phối hợp.

1.4. Ngứa. Trong nghiên cứu của chúng tôi, tỷ lệ ngứa của hai nhóm lần lượt là $26,6 \%$ và $23,3 \%$. Tỷ lệ này thấp hơn của Nguyễn Hoàng Ngọc (37,4\% ở nhóm sử dụng 0,1mg morphin và $42,31 \%$ ở nhóm sử dụng $0,15 \mathrm{mg}$ morphin) có thể do chúng tôi không sử dụng morphin khi gây tê tủy sống [8]. Tuy tỷ lệ ngứa khá cao nhưng tất cả các bệnh nhân của chúng tôi đều ngứa ở mức độ nhẹ, chịu đựng được và tự hết sau 1-2 giờ và không cần điều trị. 
1.5. Rét run. Rét run gặp ở $26,6 \%$ bệnh nhân nhóm gây tê tủy sống và $13,3 \%$ bệnh nhân ở nhóm gây tê tủy sống - ngoài màng cứng phối hợp, không có sự khác biệt với $p>0,05$. Rét run tuy không nguy hiểm nhưng gây khó chịu cho bệnh nhân. Cơ chế của rét run sau gây tề vùng đến nay vẫn chưa được hiểu biết đầy đủ nhưng thường gặp trong các trường hợp sản phụ lo lắng, nhiệt độ môi trường lạnh, truyền nhiều dịch, nhất là truyền vào bệnh nhân dịch lạnh, do kích thích các ổ cảm thụ nhiệt của ống sống do thuốc tê lanh. Có thể giải thích kết quả của chúng tôi: một phần là do truyền nhiều dịch và truyền tốc độ nhanh trong gây tê. Các bệnh nhân rét run của chúng tôi đều được điều trị dễ dàng bằng ủ ấm, nếu không đơ thì tiêm tĩnh mach $30 \mathrm{mg}$ dolargan.

1.6. Bí tiểu. Bí tiểu là do tác dụng của thuốc tê lên tủy sống do ức chế thần kinh phó giao cảm chi phối bàng quang làm giãn cơ vòng bàng quang gây tăng thể tích tối đa của bàng quang. Trong nghiên cứu của chúng tôi không có bệnh nhân có bí tiểu sau khi rút sonde tiểu 24 giờ sau mổ lấy thai, không có sự khác biệt có ý nghĩa thống kê giữa hai nhóm.

1.7. Đau đâu. Trong nghiên cứu của chúng tôi không gặp trường hợp nào đau đầu sau gây tê ở cả hai nhóm. Có thể giải thích điều này là do chúng tôi gây tê tủy sống bằng kim nhỏ loại 27G. Điều này cho thấy: Phương pháp gây tê tủy sống - ngoài màng cứng phối hợp nếu không gây thủng màng cứng khi gây tề ngoài màng cứng thì tỷ lệ đau đâuu sẽ không khác biệt so với gây tê tủy sống đơn thuần.

2. Tác dụng không mong muốn trên con. Tất cả các trẻ sơ sinh của hai nhóm đều có điểm Apgar phút thứ nhất và phút thứ 5 lớn hơn 8 điểm, không gặp trẻ sơ sinh nào cần hỗ trợ hô hấp hoặc hồi sức sơ sinh. Tuy nhiên, để đánh giá tác động của phương pháp vô cảm trên thai nhi cần xét nghiệm $\mathrm{pH}$ máu động mạch rốn của trẻ sơ sinh, nghiển cứu của chúng tôi không làm xét nghiệm này, đây cũng là hạn chế của nghiên cứu của chúng tôi, tuy nhiên, theo các nghiên cứu nước ngoài, chỉ số này cũng không khác biệt giữa sơ sinh của bà me được vô cảm bằng hai phương pháp trên, có thể do thời gian tụt huyết áp trong mổ của hai nhóm đều không kéo dài nên ít ảnh hưởng đến tình trạng sơ sinh [5], [6].

\section{KẾT LUÂN}

Trong vô cảm để mổ lấy thai ở sản phụ có nguy cao tụt huyết áp, phương pháp gây tề tuỷ sống - ngoài màng cứng phối hợp (liêu $5 \mathrm{mg}$ bupivacaine kết hợp với ngoài màng cứng $10 \mathrm{ml}$ lidocain $1 \%$ và bổ sung lidocain ngoài màng cứng nếu cần) ít gặp nôn, buồn nôn hơn so với phương pháp gây tể tủy sống đơn thuần $(6,67 \%$ so với $23,3 \% ; p<0,05)$. Các tác dụng không mong muốn khác trên mẹ và con không có sự khác biệt giữa hai nhóm (Tỷ lệ ngứa, rét run ở nhóm gây tê tuỷ sống - ngoài màng cứng phối hợp là $23,3 \%$ và $13,3 \%$ so với $26,6 \%$ và $26,6 \%$ ở nhóm gây tê tủy sống đơn thuần; không gặp bênh nhân nào bi suy hô hấp, an thần sâu, đau đầu, bí tiểu ở cả hai nhóm. Điểm Apgar phút thứ nhất và phút thứ 5 của trẻ sơ sinh ở hai nhóm đều > 8, không có sự khác biệt). Không gặp các biến chứng nguy hiểm trên mẹ và con.

\section{TÀI LIÊU THAM KHẢO}

1. Corke BC, Datta S, Ostheimer GW, Weiss JB, Alper MH. Spinal anaesthesia for Caesarean section. The influence of hypotension on neonatal outcome. Anaesthesia. Tháng Sáu 1982;37(6):658-62.

2. Kiefer RT, Ploppa A, Dieterich HJ. [Aortocaval compression syndrome]. Anaesthesist. Tháng Mười-Một 2003;52(11):1073-83; quiz 1084.

3. Roofthooft E, Van de Velde M. Low-dose spinal anaesthesia for Caesarean section to prevent spinal-induced hypotension. Curr Opin Anaesthesiol. Tháng Sáu 2008;21(3):259-62.

4. Choi D-H, Ahn H-J, Kim J-A. Combined lowdose spinal-epidural anesthesia versus single-shot spinal anesthesia for elective cesarean delivery. Int J Obstet Anesth. Tháng Giêng 2006;15(1):13-7.

5. Teoh WHL, Thomas E, Tan HM. Ultra-low dose combined spinal-epidural anesthesia with intrathecal bupivacaine $3.75 \mathrm{mg}$ for cesarean delivery: a randomized controlled trial. Int J Obstet Anesth. 1 Tháng Mười 2006;15(4):273-8.

6. Wang LZ, Zhang YF, Hu XX, Chang XY. A randomized comparison of onset of anesthesia between spinal bupivacaine $5 \mathrm{mg}$ with immediate epidural $2 \%$ lidocaine $5 \mathrm{~mL}$ and bupivacaine $10 \mathrm{mg}$ for cesarean delivery. Int J Obstet Anesth. 1 Tháng Hai 2014;23(1):40-4.

7. Nguyễn Đức Lam. Đánh giá hiệu quả của phương pháp gây tê tuỷ sống và gây tê tuỷ sống Ngoài màng cứng phối hợp để mổ lấy thai ở bệnh nhân tiền sản giật nặng. đại học y Hà Nội; 2013.

8. Nguyễn Hoàng Ngọc. Đánh giá tác dưng gây tê dưới màng nhện bằng bupivacain liều thấp kết hợp với fentanyl trong mố lấy thai. 2003. 